\title{
O Caráter Imagético da Tipografia: As Raízes Futurístas do Uso das Palavras Enquanto Imagem.
}

The Imagetic Character of Typography: The Futurist Roots of The Use of Words as Image.

Genilda Oliveira de Araujo ${ }^{1}$, Gabriela Botelho Mager² 


\section{Resumo}

O caráter imagético do texto passou a ser propagado por movimentos questionadores da arte e da sociedade, como o futurismo e o dadaísmo no início do século XX, tornando-se referência para outros movimentos de contracultura de 1980 em diante, principalmente no campo do design gráfico. Busca-se, neste trabalho, abordar o significado deste tipo de composição tipográfica em que a palavra entra com força de imagem, analisando diferentes formas futuristas e dadaístas de exploração do texto, nos trabalhos de Marinetti, Apollinaire e Zdanevich, bem como suas pretensões semânticas, tecendo-se relações com movimentos mais contemporâneos, exemplificados nos projetos gráficos das revistas The Face, SoDA, Beach Culture e Zembla. Tipógrafos, artistas gráficos e designers questionaram em seus trabalhos as regras tipográficas estabelecidas resultando uma nova forma de criação da composição tipográfica, na qual a desconstrução e o uso da palavra como imagem são fundamentais para a criação de novos significados na página.
The imagistic character of the text began to be disseminated in the beginning of the twentieth century by movements that questioned art and society, such as Futurism and Dadaism, becoming a reference for other counterculture movements from 1980 onwards, mainly in the field of graphic design. The aim of this study was to address typographic compositions in which the word has an image value, by analyzing experiments with text created by Futurists and Dadaists such as Marinetti, Apollinaire and Zdanevich as well as their semantic propositions, establishing relations with more contemporary movements, exemplified in the graphic designs of magazines like The Face, soDA, Beach Culture and Zembla. Typographers, graphic artists and designers in their work have questioned the typographic rules of harmony, resulting in the creation of a new form of typesetting, in which deconstruction and the use of the word as image are fundamental to the creation of new meanings on the page.

Keywords: Design, Typography, Futurism
ISSN: 1808-3129
Palavras-Chave: Design, Tipografia, Futurismo.

(n)

\footnotetext{
${ }^{1}$ Mestre em Ciências da Computação pela Universidade Federal de Santa Catarina, diretora de criação do Claren Design Ltda, Brasil; Florianópolis - SC - Brasil; genilda@gmail.com
}

${ }^{2}$ Orientadora, Prof. Dra. da Universidade do Estado de Santa Catarina UDESC

Florianópolis - SC - Brasil; gabriela.mager@udesc.br 


\section{Introdução}

A escrita, na medida em que codifica visualmente a linguagem oral, carrega em si não apenas o componente verbal primeiro que a originou, mas se reveste de formas que lhe dão uma dimensão gráfica. Ao cruzar a fronteira fonética e se transformar em um objeto para os olhos, o texto perde o conjunto de informações sonoras que contribuem para a formulação de seu significado, ganhando, por outro lado, elementos visuais que sinestesicamente passam a moldar sua semântica.

Mesmo a página de texto mais sóbria, meticulosamente composta para não interferir no conteúdo verbal nela contido, carrega sutilmente a mensagem, ou o convite, para um mergulho na leitura. O simples folhear de diferentes livros de texto transmite a mais variada gama de mensagens. Por exemplo, há aqueles que encantam pela beleza com que o texto preenche suas páginas; alguns oprimem pelo excesso de palavras; outros repelem pelo peso ou forma de suas letras. Assim, antes mesmo de alguém se debruçar sobre a leitura, o mero vislumbrar de uma página já estabelece comunicação, pois todo texto é imagem, esteja ele escrito manualmente, impresso ou visualizado em uma tela digital.

Este caráter imagético do texto passou a ser amplamente considerado a partir dos movimentos questionadores da arte e da sociedade, como o futurismo e o dadaísmo. Relacionavam suas composições como uma maneira de questionar as regras tipográficas e sociais estabelecidas, tendo marcado o início do século XX e se tornado referência para outros movimentos de contracultura da década de 1980 em diante.

Considerando a representatividade desta contribuição dentro do campo do design gráfico, o presente artigo busca abordar o significado deste tipo de composição tipográfica em que a palavra entra com força de imagem, sendo analisadas as diferentes formas futuristas e dadaístas de exploração do texto, bem como a suas pretensões semânticas, tecendo-se relações com movimentos posteriores que beberam de sua fonte.

\section{Materiais e Métodos}

Este trabalho caracteriza-se como uma pesquisa aplicada, pois se pretende que os resultados obtidos possam servir de referência para a estruturação de layouts de páginas que explorem a tipografia como imagem. O seu desenvolvimento foi realizado principalmente com base em uma pesquisa bibliográfica sobre os usos da tipografia para diagramação no início do século XX, resultando na confecção de um texto com uma história concisa.

Por se tratar de um trabalho com base estritamente histórica e teórica, cabem aqui algumas considerações. A primeira delas diz respeito à seleção do conteúdo a ser incluído. É importante deixar claro que o que aqui se apresenta são recortes desta história. Também é importante comentar que o critério de seleção destes recortes é o impacto, de acordo com a bibliografia disponível, que certas estruturas e formas tipográficas tiveram sobre a construção da cultura e da linguagem tipográficas, tanto por questões funcionais quanto por questões semânticas.

Por fim, é preciso comentar que este trabalho contém uma breve pesquisa imagética das peças gráficas mais relevantes para cada recorte, buscando clarificar com exemplos o conteúdo teórico apresentado. Esta coleta de imagens foi feita funda- 
mentalmente com base na bibliografia disponível, complementando-se com material obtido via internet.

\section{A tipografia a serviço da harmonia na leitura}

Fazendo um retrospecto histórico, desde a antiguidade, escribas e tipógrafos se dedicaram a tarefa de configurar o espaço visual da página. Tradicionalmente, a característica semântica que se buscava atingir na produção da página era a harmonia, de modo que o texto agradasse ao olho e a mente do leitor. Com esse intuito, livros do Renascimento e manuscritos do Antigo Egito, México Pré-Colombiano e Roma Antiga eram feitos com base em proporções recorrentes na natureza, tais como como a seção áurea e aquelas encontradas em figuras geométricas como o círculo, o quadrado, o hexágono e o octógono (BRINGHURST, 2005, p. 160). Nestes documentos clássicos, era o fluxo da escrita, contínuo e linear, que mantinha a página homogênea: letras formando palavras, ordenadas em linhas horizontais, coluna a coluna, página a página. Esta placidez formal e estrutural pode ser claramente visualizada em páginas renascentistas como as do livro "De Aetna", impresso em 1495 na Itália pelo tipógrafo Aldo Manuzio, mostradas na figura 1.

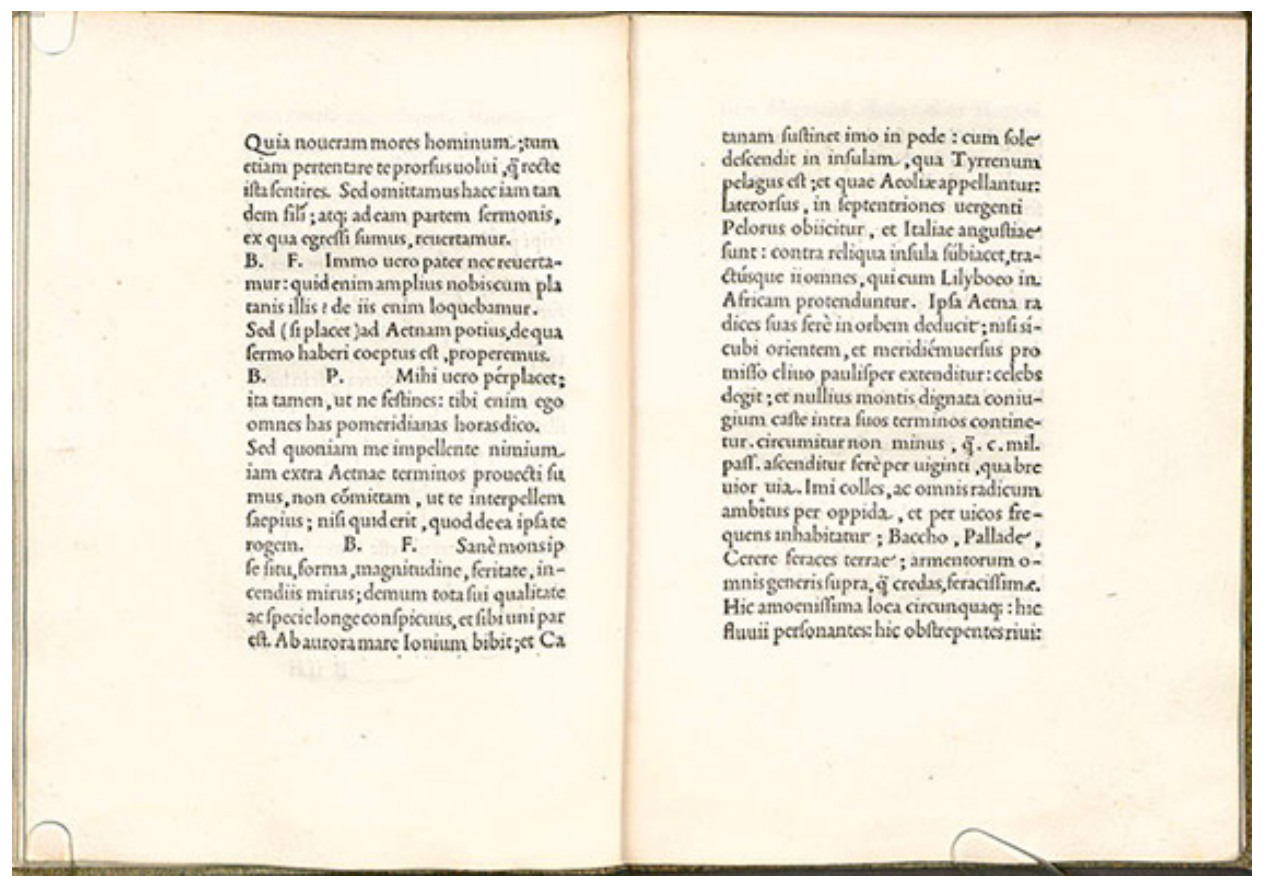

Figura 1 - Página do livro "De Aetna", impressa em 1495

(fonte: http://commons.wikimedia.org/wiki/File:De_Aetna_1495.jpg)

O uso da linearidade como elemento estrutural da página se manteve praticamente inalterado até o início do século XX, parecendo ser uma convenção imutável. Mesmo nos anúncios publicitários que haviam surgido, apesar da variedade de tipos e tamanhos numa mesma página, sua diagramação era fundamentalmente linear. Nos cartazes e nas capas dos livros, as palavras se colocavam de forma simétrica, seguindo uma hierarquia de importância, construída com base na variação de tamanhos dos tipos. Havia poucos esforços para compor as palavras de modo que seu significado, individual ou coletivo, fosse destacado mediante sua aparência (MARCH, 2012, p. 19). A mancha gráfica não era construída para expressar a delicadeza ou o vigor do texto. 
A proposta era tornar a página o maios harmoniosa possível para que se ter o melhor nível de leiturabilidade.

Independentemente deste direcionamento conceitual, qualquer inclinação para construir páginas com estruturas diferentes esbarrava em um empecilho tecnológico. No início do século XX, a maior parte da impressão de texto era feita por tipografia, processo que se baseia na ideia de agrupar sequencialmente um conjunto de tipos móveis para formar linhas que, por sua vez, compõem juntas a matriz de impressão de uma página, conforme mostrado na figura 2.

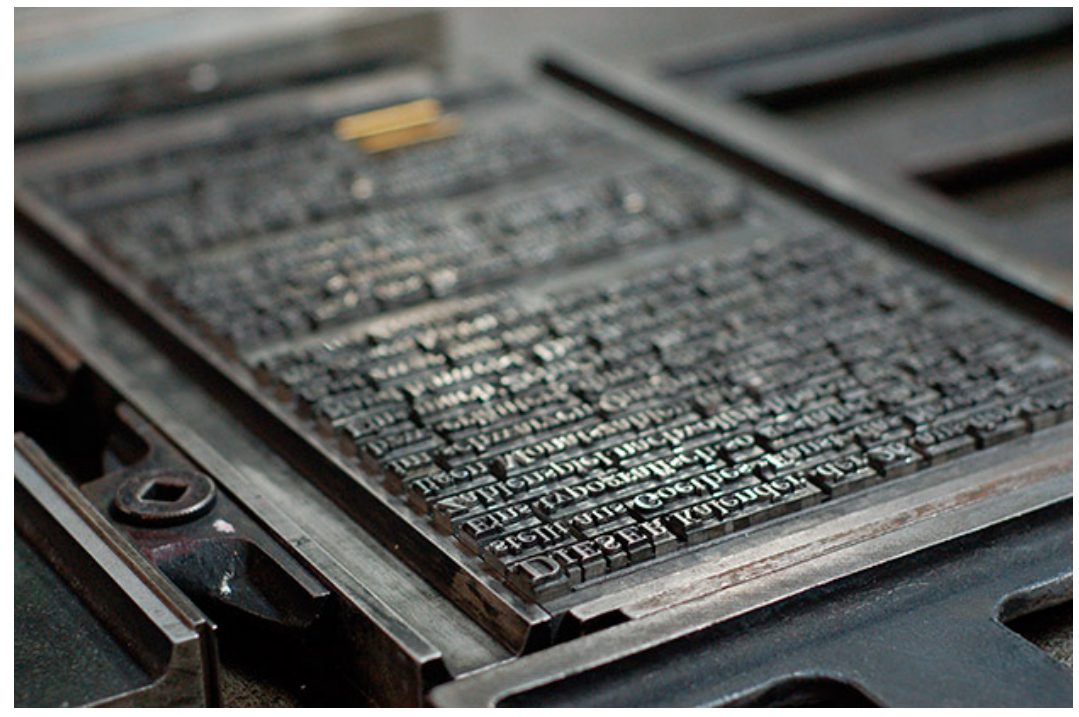

Figura 2 - Exemplo de matriz tipográfica, onde pode ser percebida a linearidade imposta pelo processo de impressão.

(fonte: http://commons.wikimedia.org/wiki/File:2009-04-18-noerdlingen-rr-05.jpg)

Este panorama de rigidez formal começou a se transformar a partir do trabalho de um grupo de poetas que fundou o movimento Futurista em 1909 na Itália. Livres das preocupações com a tradição, pretendiam animar suas páginas com uma composição dinâmica e não linear (MEGGS, 2009, p. 321). Para conseguir este intento, não se deixaram condicionar pelos limites aparentemente impostos pela tecnologia, usando de extrema engenhosidade para manipular as matrizes tipográficas de forma não convencional. Em suas explorações visuais, combinavam uma ampla variedade de tipos muito diferentes em peso, tamanho e desenho. O distanciamento da simetria e da horizontalidade conferia a estas composições uma sensação de movimento e vitalidade (SPENCER, 1990, p. 60). A figura 3 mostra uma página dupla da revista "Blast", diagramada em 1914 por Wyndham Lewis segundo os princípios futuristas.

Nos anos posteriores ao surgimento do Futurismo, mudanças técnicas na impressão aliadas a mudanças sociais ajudaram a borrar as fronteiras entre as artes gráficas, a poesia e a tipografia, situando esta última em um plano mais visual, menos linguístico e menos puramente linear (SPENCER, 1990, p. 11). Foi o trabalho destes desbravadores italianos que plantou as sementes de um novo vocabulário gráfico e tipográfico que começou a se consolidar durante o Modernismo e que continua se expandindo até a atualidade. 


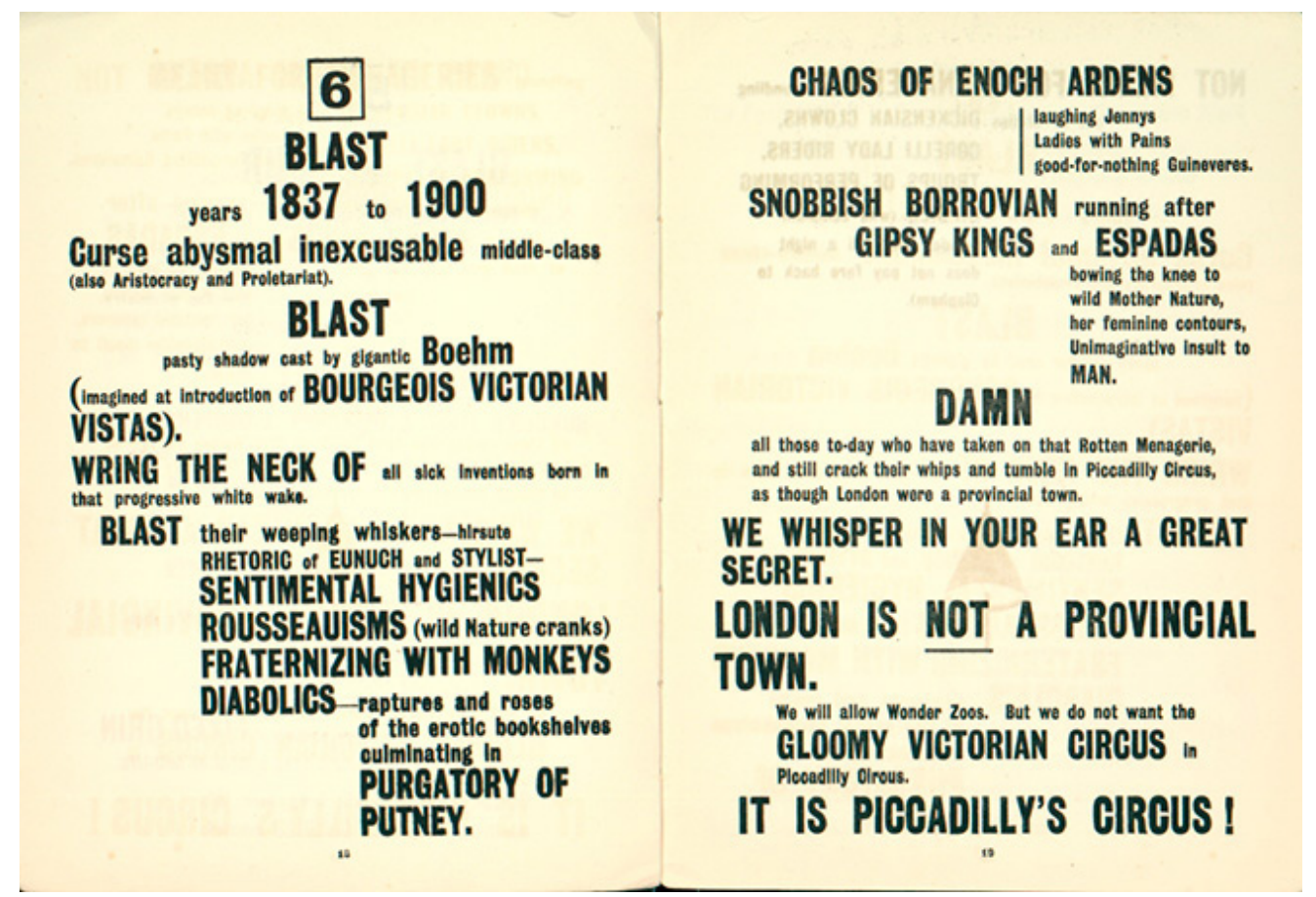

Figura 3 - Página da revista "Blast" produzida por Wyndham Lewis em 1914. (fonte: http://www.hrc.utexas.edu/educator/modules/teachingthetwenties/)

\section{O Futurismo e as palavras em liberdade}

O cenário gráfico do início do século $X X$ foi marcado pelo culminar de transformações gestadas a partir do início da Revolução Industrial. O Futurismo, cujo manifesto foi publicado em fevereiro de 1909 pelo poeta Filippo Marinetti no jornal parisiense Le Figaro, nasceu como uma reação ao status quo e ao peso opressivo do passado e das tradições que, na concepção de seus membros, tinham se tornado petrificadas e fora de lugar. Atacavam o classicismo prevalecente e o simbolismo hedonista, objetivando expressar a revolução e o movimento típicos de seu tempo. Imbuídos de excitação pelas novas tecnologias e pela velocidade, queriam reformar a literatura, as artes e a sociedade, substituindo o tradicionalismo arraigado por um novo conceito, o de modernidade (BARTRAN, 2005, p. 7). Em suas poesias, de teor lírico e lúdico, encontraram espaço para experimentar suas ideias, conferindo sinestesia ao impresso. Neste contexto, a busca por novas formas e novas configurações gráficas acabou abrindo o layout da página para a organização dinâmica e para a assimetria que se tornariam as bases do design modernista.

No entanto, sua essência não era a de um movimento estritamente visual. Seus fundadores se opunham a "arte pela arte" e rechaçavam qualquer ideia que simplesmente convidasse a brincar com formas tipográficas ou realizar inovações sem sentido (SPENCER, 1990, p. 17). A proposta era de que a tipografia fosse usada como instrumento para intensificar o conteúdo, explorando suas qualidades expressivas com o intuito de elucidar seu significado e fortificar o efeito das palavras. 
A harmonia era rejeitada como qualidade do design porque era indiferente aos saltos e explosões de estilo que perpassavam a página. Palavras livres, dinâmicas e penetrantes podiam comportar a velocidade das estrelas, nuvens, aviões, trens, ondas, explosivos, moléculas e átomos. (...) Conclamava os poetas a se libertarem da servidão à gramática e abrir novos mundos de expressão (MEGGS, 2009, p. 318).

Embalados pela ideia de dar liberdade às palavras, destruíram praticamente tudo que estava ao alcance no que diz respeito à sintaxe linguística: não elaboravam sentenças do jeito convencional e usava apenas verbos no infinitivo, abolindo adjetivos, advérbios e pontuação (HOLLIS, 2000, p. 36). Sua abordagem pretendia ampliar o poder expressivo das palavras, mas não através de nuances gramaticais, e sim de uma nova configuração gráfica que rompesse com a até então pregada harmonia tipográfica da página e que fizesse uso de todos os elementos tipográficos disponíveis para trabalhar as relações linguísticas contidas em seus poemas. O conceito futurista de que a escrita e/ou a tipografia podiam se converter em uma forma visual concreta e expressiva passou a ser uma preocupação recorrente entre seus poetas (MEGGS, 2009, p. 321).

Uma das primeiras iniciativas neste sentido foi a do poeta simbolista francês Mallarmé em 1897, precedendo o próprio movimento futurista. Neste ano, publicou um poema chamado "Un coup de dés" (um lance de dados), no qual fez um novo uso do espaço da página e do espaço entre palavras, criando uma nova dinâmica visual e de leitura por tomar o espaço em branco como sinônimo de silêncio (HOLLIS, 2000, p. 35). Mallarmé trabalhava as páginas duplas de seus livros como unidades e, através delas, seus versos eram compostos como uma partitura musical para quem quisesse lê-los em voz alta.

Ali, pela primeira vez, as palavras não viajavam sobre linhas pré-estabelecidas, mas as linhas se quebravam e continuavam mais abaixo. Tão pouco, a página era uma grade cheia de caracteres, vírgulas e pontos, mas uma geografia de palavras e espaços, em cujo interior as palavras flutuavam como uma balsa no mar (MAR$\mathrm{CH}, 2012$, p. 167).

Conforme pode ser visto na figura 4, havia diferenças de tamanho entre as partes do poema para indicar sua importância e entonação no momento em que fossem declamadas. Outro recurso usado consistia em colocar palavras ou grupos de palavras em linhas separadas formando uma composição parecida com os degraus de uma escada. Para ele, esta disposição causa uma separação mental que acelera e desacelera o movimento dos olhos, definindo um ritmo para a leitura (BARTRAN, 2005, p. 10).

Este trabalho teve repercussão entre os que posteriormente se tornariam futuristas. Através da visualização das "palavras em liberdade" de Mallarmé, Marinetti percebeu que as letras não eram meros signos alfabéticos (MARCH, 2012, p. 21). Os diferentes pesos e formas, bem como o arranjo com o qual são dispostas na página, conferiam às palavras um caráter expressivo distinto, que lhes permitiam ser usadas por si só como imagens visuais. 


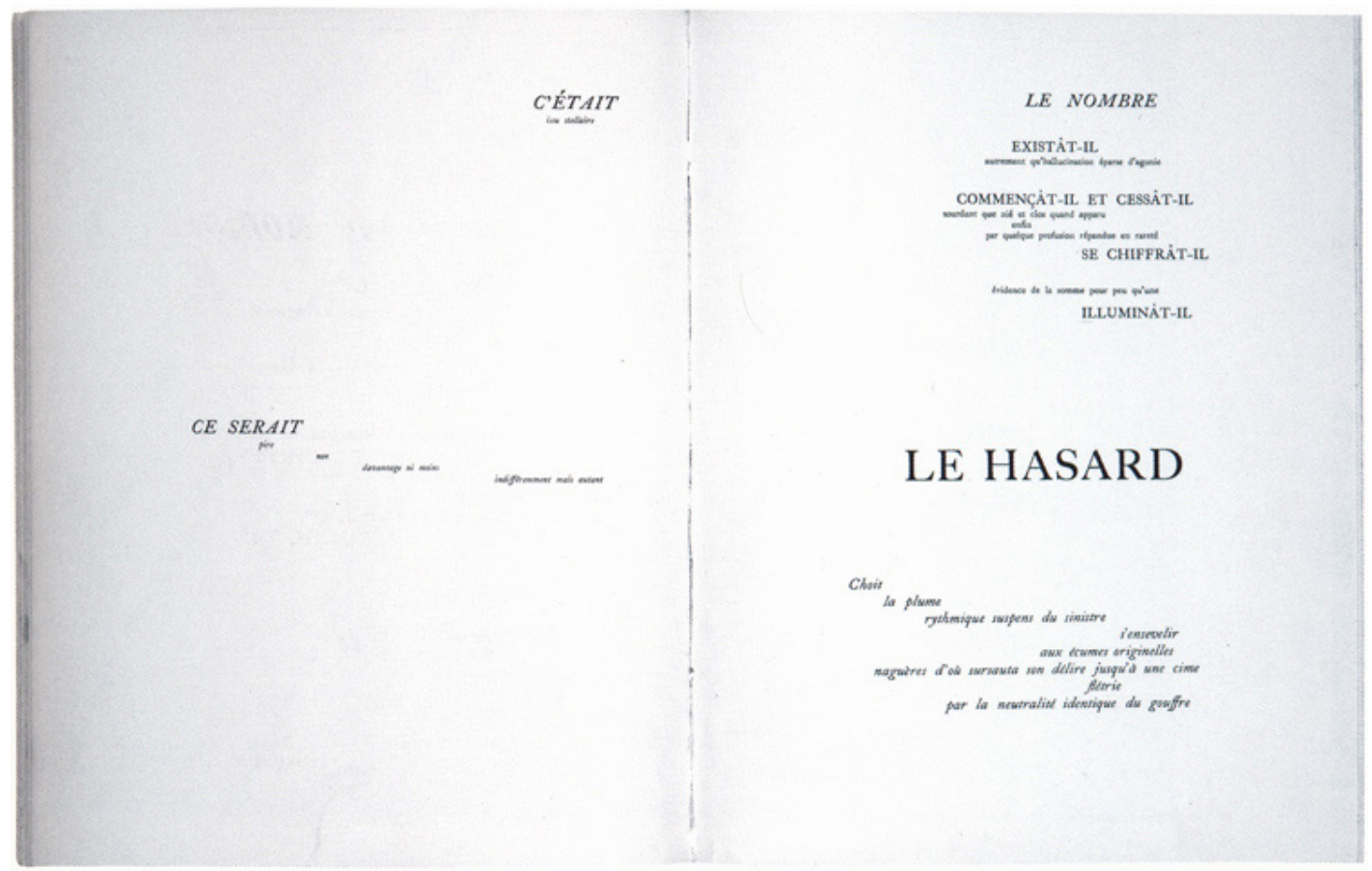

Figura 4 - Página do poema "Un coup de dés" produzido por Mallarmé em 1897. (fonte: BARTRAM, 2004, p. 11)

\section{Marinetti e a tipografia semântica}

A ruptura definitiva com a ortogonalidade da matriz tipográfica tradicional veio com Marinetti. Para ele, a construção da página não se limitava ao agrupamento sequencial e racional dos tipos. Ao contrário, moldava de forma complexa todos os elementos tipográficos que estivessem a seu alcance, incluindo a própria angulação das palavras. A resultado era uma poesia visual única, na qual o conteúdo ressoava por meio da estrutura gráfica, estabelecendo uma comunicação que atingia o leitor simultaneamente nos âmbitos verbal e visual.

Para Marinetti, a imagem de uma linha era também valor linguístico, o que tornava o poema um objeto do olhar. Ora, se uma linha pode ser pictorial e um sinal de pontuação atuar de forma teatral na página, fenomenologicamente esses signos são utilizados para provocar sensações, aumentando a sinestesia do poema (GAUDÊNCIO, 2004, p. 57).

Seu trabalho mais importante é o livro "Zang Tumb Tumb", de 1914, que conta a história de uma batalha em Trípoli, da qual havia sido testemunha como repórter. Ao longo das páginas deste livro, o caos da guerra é retratado através de uma onomatopeia ${ }^{1}$ visual onde diferentes tamanhos, pesos e estilos de fonte ganham caráter pictórico para representar estados de humor, velocidade e barulho (BARTRAM, 2004, p. 21). As palavras não trazem a semântica apenas através da linguagem verbal, mas a constroem também com sua sintaxe visual. Flutuando ao longo da página e liberto de convenções gramaticais como pontuação, o texto descreve verbalmente cores, sons e outras sensações, simultaneamente reforçadas pelas escolhas tipográficas, 
estabelecendo relações entre si. Sua proposta de trabalho pode ser compreendida observando-se a figura 5, que mostra uma passagem do livro na qual um balão turco transmite mensagens por telégrafo. Nesta composição, a disposição circular da tipografia materializa o próprio balão, a partir do qual as mensagens telegrafadas se dispersam em rajadas de texto nos mais variados ângulos. Na página oposta, o ataque às Balcãs é sonoramente apresentado (toumtoumtoum tza tzu), sendo seguido por uma escalada de $300 \%$ nos preços dos alimentos mostrada por meio de uma matriz visual de letras e números.

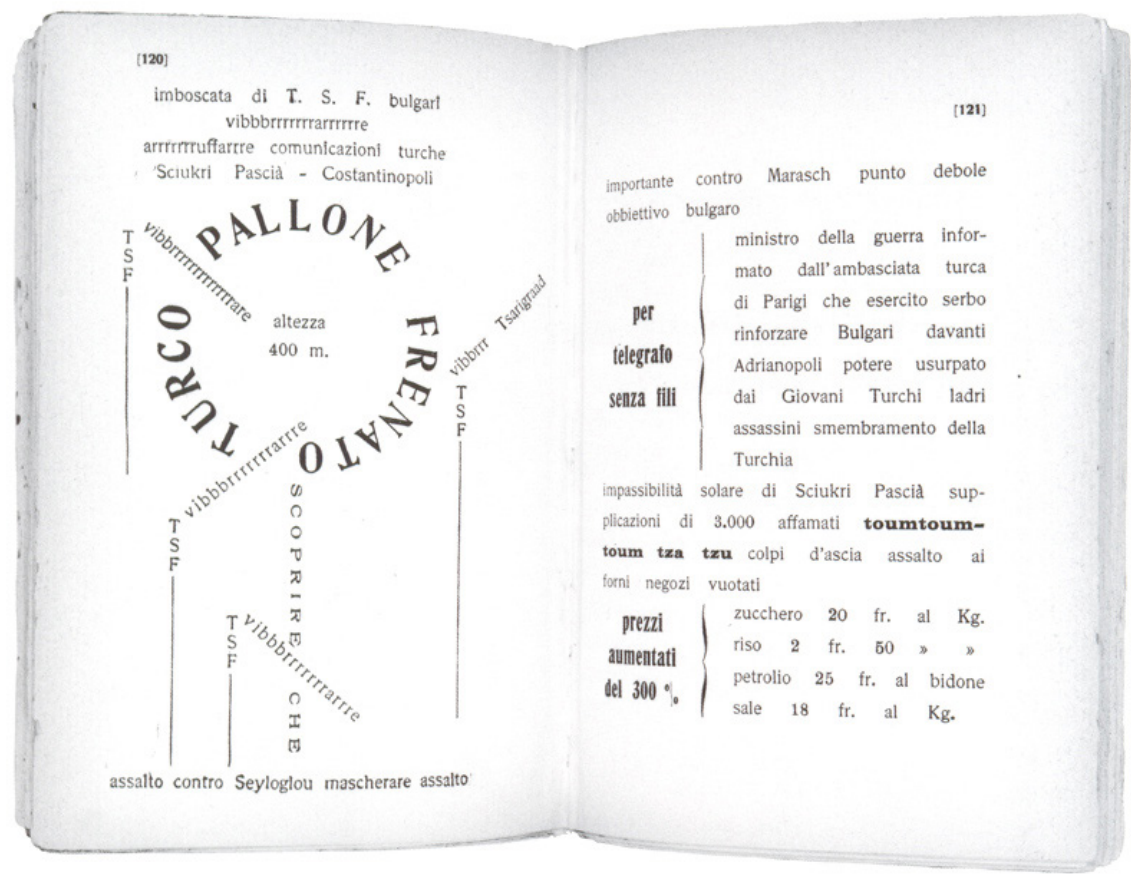

Figura 5 - Página do livro Zang Tumb Tumb (fonte: BARTRAM, 2004, p. 26)

Em alguns outros trabalhos, Marinetti usou colagem de tipos, pedaços de impressão e formas desenhadas, montando uma composição mais abstrata que também trabalhava a simultaneidade visual e linguística dos caracteres para contar uma história. A figura 6 mostra a obra "Après la Marne, Joffre visita le front en auto", que apresenta um percurso feito de carro por entre montanhas, vales e campos de batalhas, construído visualmente através de uma composição tipográfica (BARTRAM, 2004 , p. 28). Neste trabalho, um arranjo espacial composto principalmente por ampliações das letras " $M$ " e "S" é usado para reconstruir a geografia do local. Completando o cenário, sinais matemáticos e textos em corpos menores representam os elementos vistos durante o passeio, havendo também indicações sonoro-tipográficas dos pontos de batalha. 


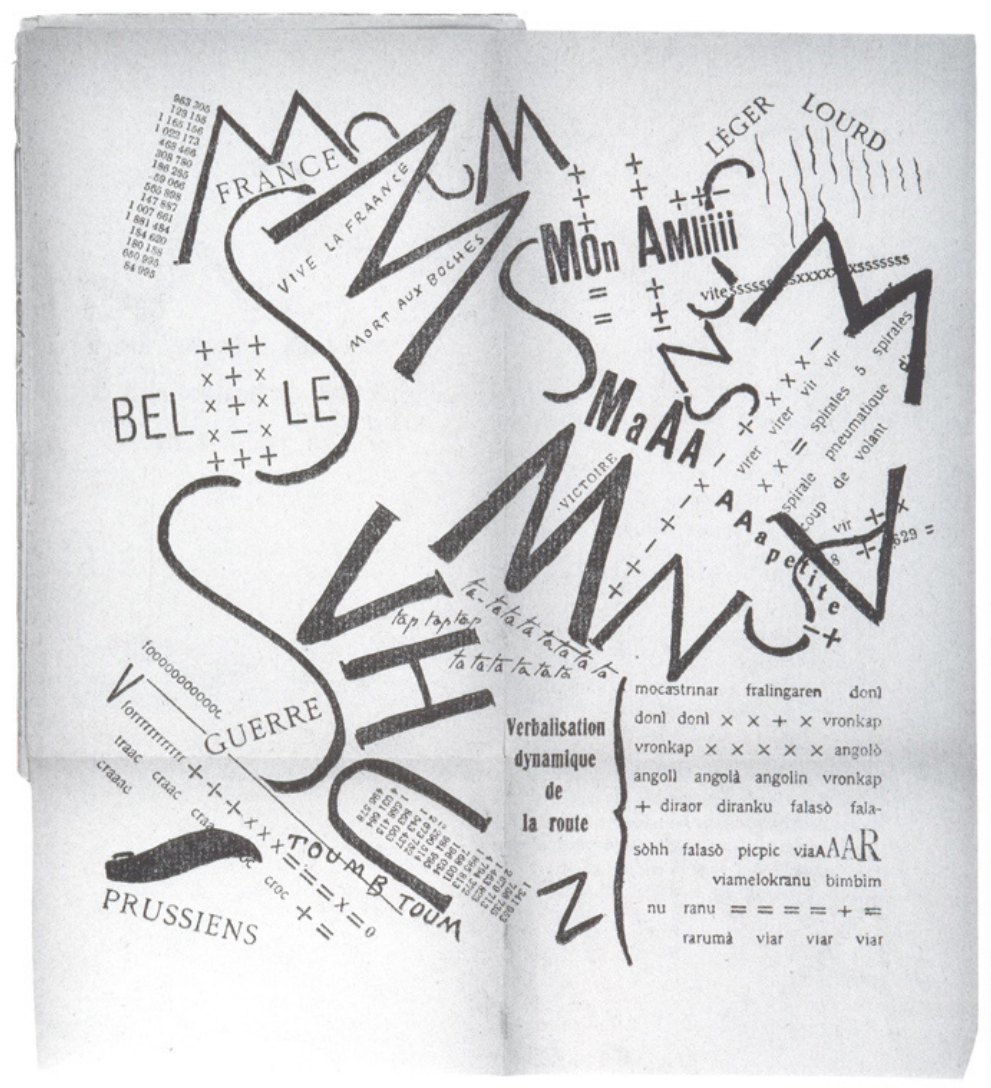

Figura 6 - Composição tipográfica de Marinetti (fonte: BARTRAM, 2004, p. 28)

\section{Apollinaire e a pintura tipográfica}

A tipografia semântica de Marinetti abriu espaço para uma série de explorações, algumas das quais diferiam bastante no uso do caráter imagético da tipografia. Em Marinetti, a configuração gráfica de cada palavra refletia e intensificava o seu conteúdo, construindo um todo de sentido. Em um nível mais amplo, a sua página refletia graficamente as relações verbais entre as palavras, criando uma tessitura visual para o poema.

Muito diferente disso era o trabalho do poeta francês Apollinaire. Seus poemas eram caligramas: peças gráficas nos quais as linhas de texto ou os caracteres eram visualmente organizados para formar uma figura relacionada com o conteúdo ou a mensagem. Um bom exemplo disso é o poema "Chove", publicado em 1914, no qual as letras são dispostas como gotas de chuva caindo do céu, o que torna perceptível a sua maneira de tratar os caracteres tipográficos como se fossem pontos ou traços usados para pintar a página. Ele simultaneamente escrevia e desenhava com os tipos que formam o poema, construindo a página tanto no sentido literário quanto no imagético. A figura 7 apresenta o poema: à esquerda aparece sua versão original, feita à mão, e à direita sua representação tipográfica. 


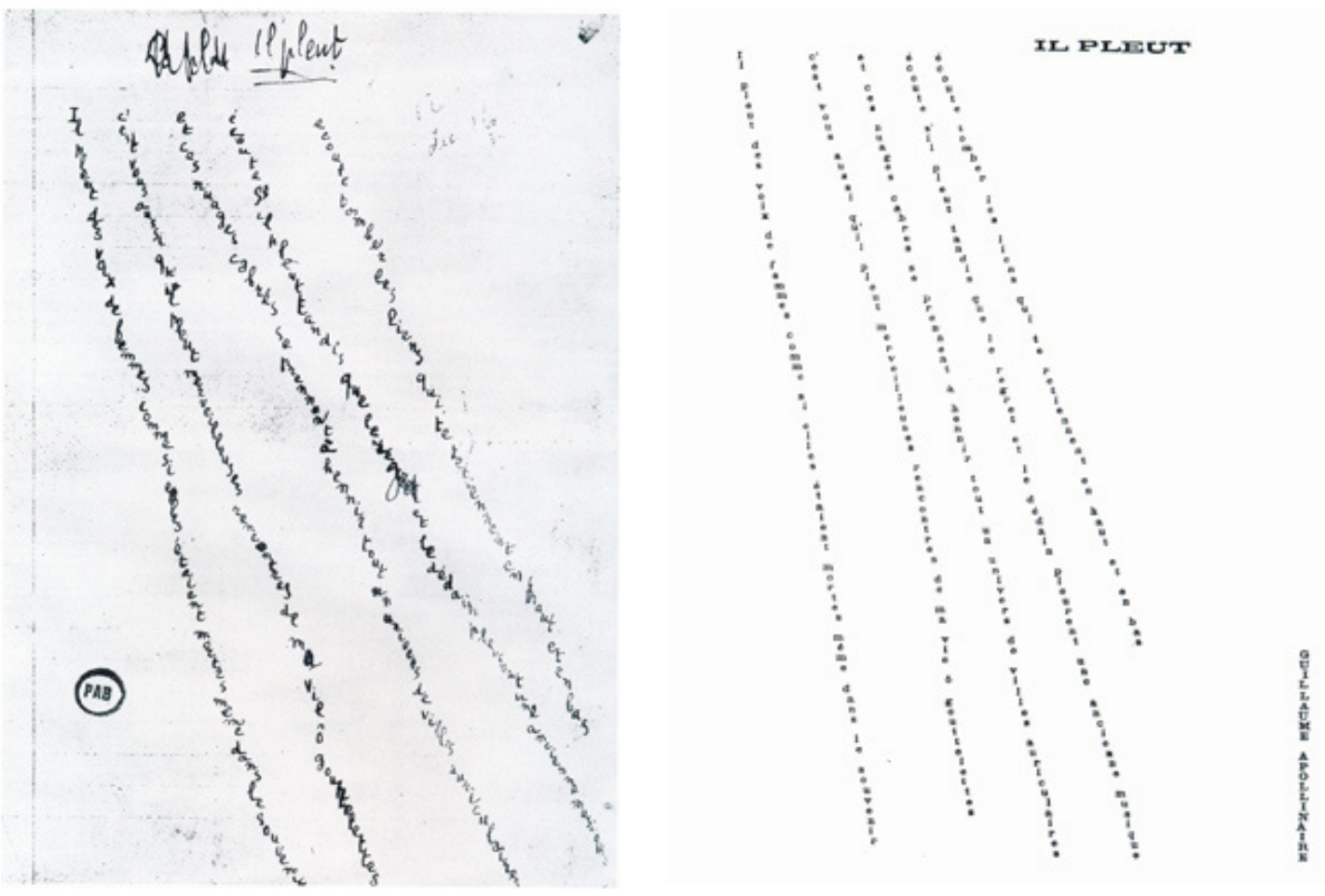

Figura 7 - 0 poema Chove de Apollinaiere (fonte: BARTRAM, 2004, p. 12)

Esta abordagem visual tem influências do cubismo sintético, que se apropriava de matérias de uso cotidiano, como jornais, papéis pintados, estopa e pregos, e os usava como elementos para produzir uma colagem. No trabalho de Apollinaire, o potencial gráfico não estava em cada letra individualmente, mas na sua articulação para criar um poema imagem, constituindo uma espécie de fusão entre poesia e pintura tipográfica.

Quando Apollinaire utiliza a tipografia como uma artista utilizaria um lápis, ele rompe não só com o valor utilitário da sintaxe tipográfica - pois os tipos até então não serviam para desenhar figuras - como também devolve a página uma sensibilidade perdida com a rigidez da imprensa (GAUDÊNCIO, 2004, p. 61).

\section{Futurismo Russo: Zdanevich e a tipografia objeto}

O movimento de liberdade para as palavras também encontrou seguidores na Rússia. No entanto, uma diferença básica em relação aos seus colegas italianos é que os russos não compartilhavam do mesmo entusiasmo pela máquina. Desta forma, ao invés de usar a matriz tipográfica como objeto de experimentação, muitos de seus livros vanguardistas eram escritos a mão ( $M A R C H, 2012$, p. 21), explorando a irregularidade e a mobilidade oferecidas pelo trabalho manual. Seus textos traziam apenas nomes e adjetivos e eram organizados pela semântica contextual e por links visuais. Neste sentido, criaram uma linguagem "transracional" e universal chamada "Zaum" que, segundo eles, era voltada para o homem do futuro (BARTRAN, 2005, p. 32), indo além da fronteira das palavras para explorar a intuição.

O poeta russo mais engajado com tipografia foi llya Zdanevich que, diferentemente dos demais futuristas russos, baseava seu trabalho em impressão. Diagramava 
o texto de maneira assimétrica, posicionando tanto ornamentos tipográficos quanto caracteres ampliados e em negrito de forma arbitrária ao longo da mancha gráfica, tomando partido da força de suas formas para compor a paisagem da página. Muito mais do que uma codificação fonética, o tipo tinha valor enquanto imagem. O objetivo por traz dessa abordagem era criar uma linguagem mais adequada para as emoções, sendo mais irracional.

Ao estressar o aspecto visual da palavra, Zdanevich questionava o signo tipográfico como uma imagem acústica, uma mera convenção a fixar o som no suporte, pois em seus poemas esse signo deixa de representar algo para se tornar uma experiência física visceral. Com isso, cada letra possui um valor que só se manifesta e pode ser medido em relação à outra letra, por escalas, pesos e medidas. O tipo gráfico independente da palavra, um objeto cravado na página (GAUDÊNCIO, 2004, p. 64).

A figura 8 mostra uma página do livro "Le-Dantyu as Beacon", na qual é possível perceber o destaque que o poeta dá a cada letra para compor expressivamente a página. Sua abordagem aqui é diferente das palavras semanticamente intensificadas de Marinetti ou da construção pictórica do discurso nas poesias de Apollinaire.

\section{O dadaísmo}

Muito ligado ao Futurismo, o movimento dadaísta também pretendia libertar o texto da linearidade visual e da sintaxe rígida, podendo, neste sentido, ser considerado uma vertente do próprio Futurismo. Apesar desta convergência na proposta gráfica, os dois movimentos se distinguiam com base no ideário que animava suas ações. Enquanto os futuristas tinham uma visão positiva da modernidade, os dadaístas surgiram como uma reação aos horrores da Primeira Guerra Mundial, possuindo um forte componente negativo que os fazia se posicionarem como um movimento anti-arte. No entanto, apesar de se contraporem ideologicamente, os dadaístas continuaram trilhando o caminho tipográfico aberto pelos futuristas no desenvolvimento da palavra imagem, motivo pelo qual este movimento teve grande relevância para o design gráfico e continua servindo como referencia para diversos trabalhos contemporâneos.

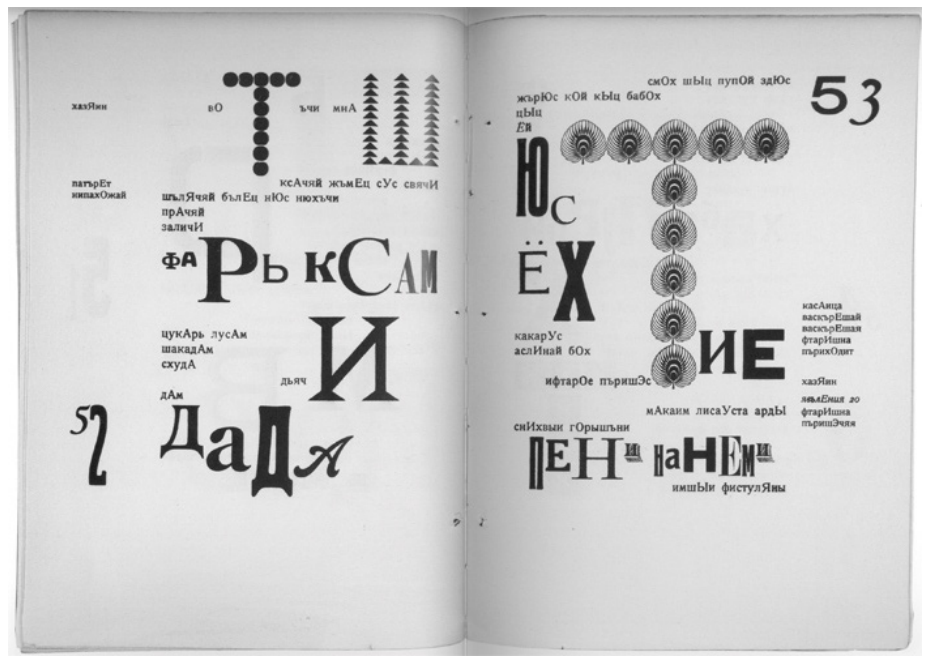

Figura 8 - Le-Dantyu as Beacon de Zdanevich (fonte: BARTRAM, 2004, p. 66) 
Suas origens como movimento literário remontam a 1916, em Zurique na Suíça, tendo aparecido após a abertura do Cabaré Voltaire, ponto de encontro de jovens poetas, pintores e músicos independentes. Em seus trabalhos, parodiavam os valores de uma sociedade que julgavam enlouquecida e usavam poemas sonoros e visuais para expressar o desejo de substituir o absurdo lógico do homem por um absurdo ilógico (MEGGS, 2009, p. 327).

Diferentemente dos futuristas, não buscavam aplicar a seus materiais gráficos novas formas de estruturação dinâmica do texto. Ao contrário, abandonaram a estrutura e tomaram partido do acaso e da falta de lógica. Por não possuírem uma visão utópica da sociedade, ao invés de tentarem dar mais força e expressão ao significado do texto, como faziam os futuristas, trabalhavam com a ausência de significado, separando a palavra do seu contexto linguístico. Muitos dos seus poemas eram padrões de números e letras criados para enfatizar apenas seu som, sem preocupação com conteúdo, como no "Phonetic Poem" de Raoul Hausmann, mostrado na figura 9.

Para construir visualmente páginas que representassem as loucuras destes mundo, o dadaístas utilizavam a técnica cubista da colagem. No entanto, foram mais longe que estes ao decidirem usar lixo como material de seus trabalhos, o que pode ser visto em alguns quadros de Kurt Schwitters (SPENCER, 1990, p. 21). A Revista "MERZ" produzida por Schwitters e exemplificada na figura 10, bem como os trabalhos de Hannah Hoch e Raoul Hausmann, demonstravam o grande potencial da fotomontagem, que posteriormente seria amplamente usada no design gráfico.

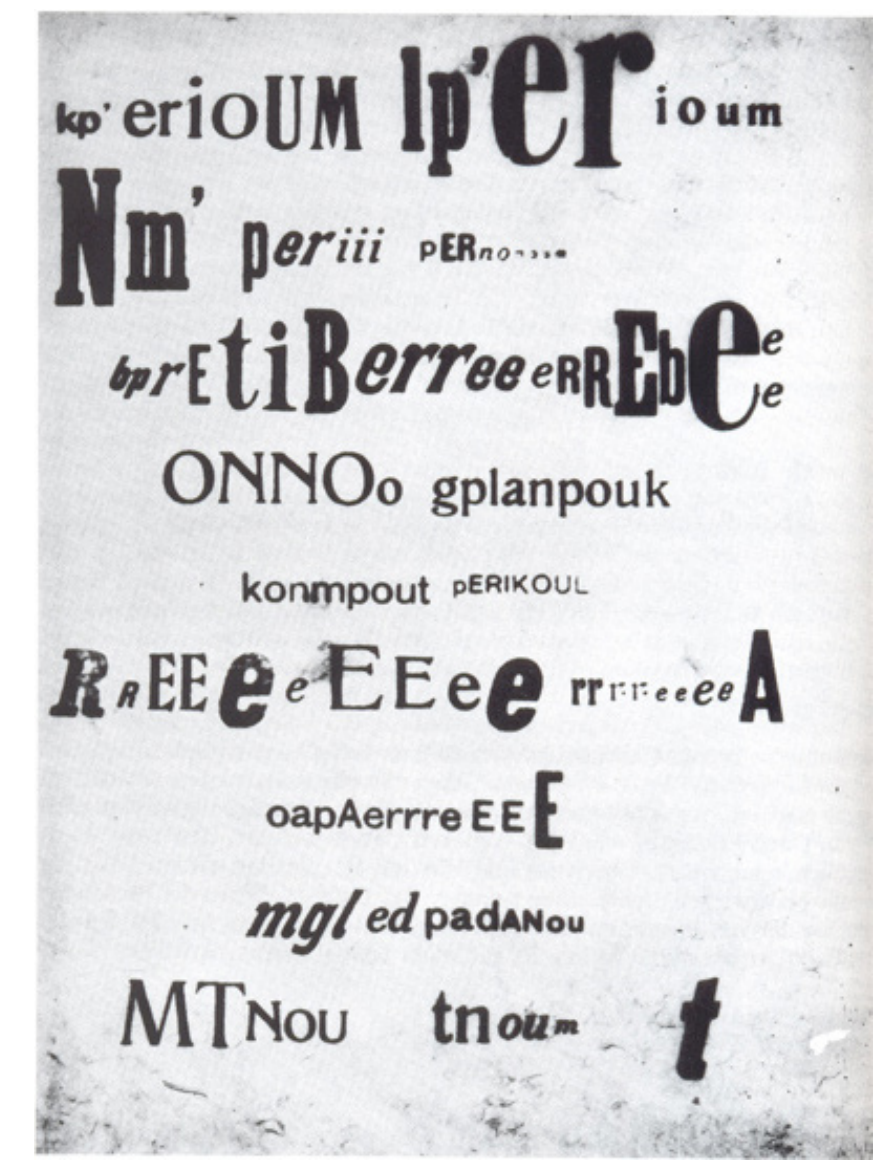

Figura 9 - Phonetic Poem de Raoul Hausmann (fonte: BARTRAM, 2004, p. 76) 


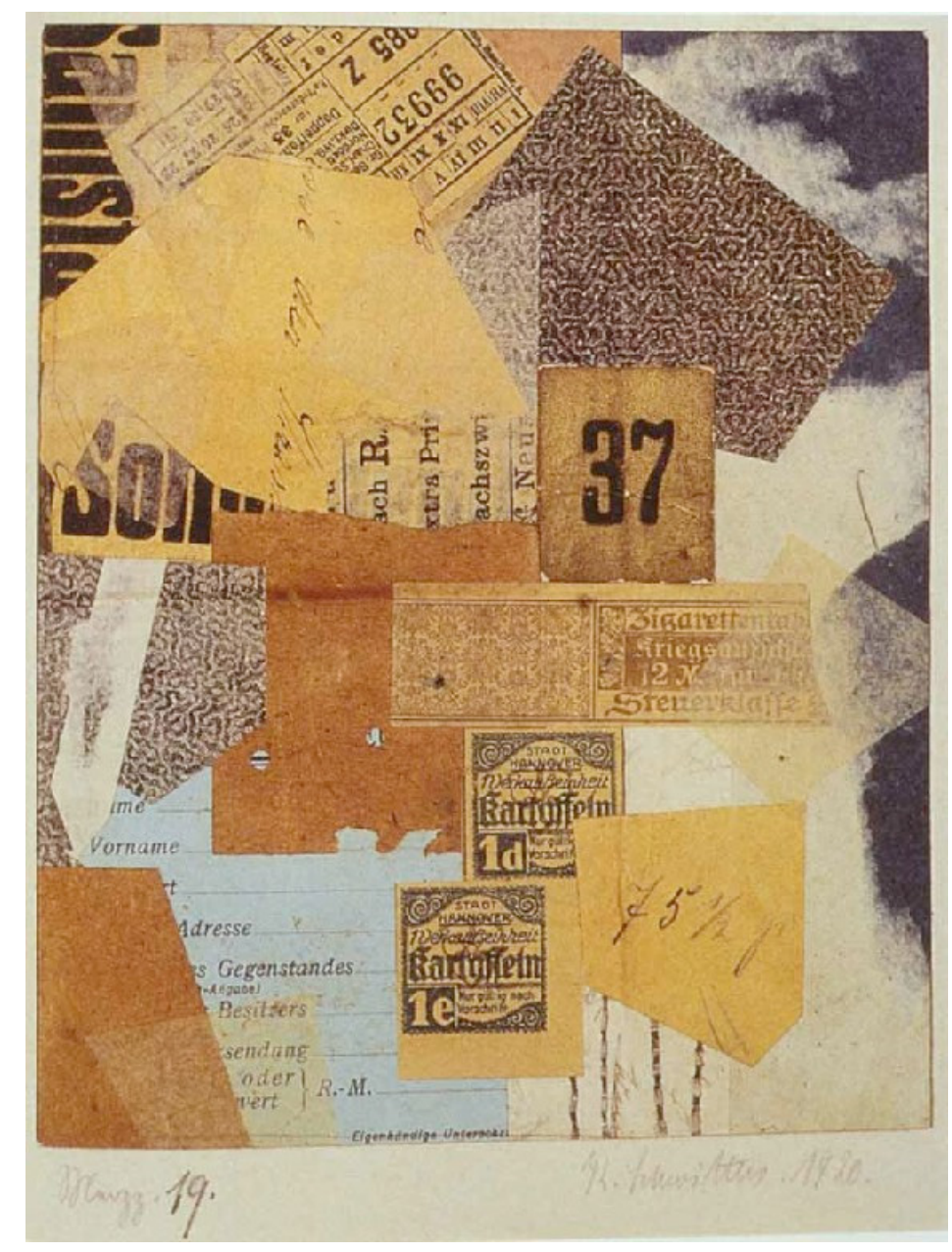

Figura 10 - Página da Revista MERZ, n 19, de Kurt Schwitters.

(fonte: http://www.studyblue.com/notes/note/n/europe-and-america-1900-1945/deck/3340103)

\section{Das palavras em liberdade às palavras imagem}

O movimento Futurista pode ser considerado a fonte de todas as liberdades tipográficas desenvolvidas a partir da década de 1920, incluindo, por exemplo, a dinamicidade de layout, a assimetria, o uso de tipos grandes e pesados em contraste com formas menores e o abandono da harmonia da página (BARTRAN, 2005, p. 8). Assim, estes vanguardistas abriram as comportas que represavam a tipografia, gerando uma onda de transformações no seu tratamento visual, permitindo o reconhecimento do poder sinestésico da letra.

Se o ponto de partida foram as palavras em liberdade, o ponto de chegada, as palavras imagem, encontram-se algumas braçadas a frente. No primeiro caso, o poder visual da palavra estava estritamente relacionado ao seu conteúdo verbal, como um potencial amplificador de seu significado poético e literário, explorado a partir de sua colocação topográfica sobre a página (MARCH, 2012, p. 176). No caso da palavra imagem, presente em Zdanevich e nos dadaístas, a premissa literária é dispensada, permitindo que o valor imagético da tipografia seja explorado de forma autônoma e não subordinado a uma conteúdo verbal específico. E este é o tipo de encaminhamento visual percebido nos materiais gráficos desenvolvidos posteriormente com base nos trabalhos futuristas e dadaístas.

O período compreendido entre o fim dos anos 1960 e a década de 1970 se 
caracterizou pelo questionamento de vários aspectos estabelecidos na sociedade até então. Surgiram movimentos críticos que pregavam uma nova estrutura social, o amor livre, o feminismo, novos valores culturais, dentre outras questões. A década de 1980 consolidou e popularizou grupos de contracultura, que por meio de produtos da indústria cultural - música, cinema, moda e design gráfico - passaram a utilizar a desconstrução como elemento estético que espelhava o desejo de romper com os paradigmas existentes. A tipografia, dentro deste panorama, era uma de suas principais forças.

A fim de exemplificar os desdobramentos da aplicação da tipografia enquanto imagem nos últimos anos, serão apresentados trabalhos de alguns diretores de arte de revistas "underground" que se destacaram, recebendo premiações e notoriedade por projetos gráficos diferenciados e desconstruídos. A opção por apresentar projetos de revistas foi feita por demonstrarem a aplicação do aspecto imagético da tipografia em materiais com grandes volumes de conteúdo, tarefa que envolve grande complexidade.

O primeiro nome que merece destaque é David Carson, tendo sido considerado uma das grandes revelações do design gráfico contemporâneo. Na década de 1980, era um jovem apaixonado por surfe e skate, esportes radicais cujos praticantes buscavam um estilo de vida aventureiro. Oriundo da sociologia e sem formação em design gráfico, arriscou-se na direção de arte da revista "Transworld Skateboarding", onde firmou seu estilo de composição de layouts ilegíveis, contrários a todas as regras tipográficas. Em 1983, participou de um workshop de três semanas sobre design ministrado por Hans-Rudolf Lutz, na Suiça, onde aprendeu sobre as regras tradicionais e não-tradicionais da composição tipográfica. Em 1989, lançou a "Beach Culture", revista na qual trabalhou três anos até seu fechamento por falta de anunciantes. Durante este período, recebeu cerca de 150 prêmios pelo projeto gráfico. A seguir, atuou na "RayGun", revista de rock alternativo. Nas três revistas, imprimiu a desconstrução do grid e a valorização do texto como imagem, por vezes, em detrimento ao conteúdo, como se pode observar na figura 11. Para ele, a imagem formada pela mancha gráfica do texto e as fotografias eram os elementos mais importantes da página. Percebe-se uma forte influência dadaísta e da poesia concreta, onde a organização das palavras e a forma criada eram fundamentais para seu efeito e significado (ZAPPATERRA, 2008, p:168). Além disso, também explorava possibilidades que só um meio digital de composição pode oferecer como sobreposição de linhas de texto, espaçamento entre letras muito apertado e criação de blocos de texto de contorno irregular (SAMARA, 2002, p. 119). 


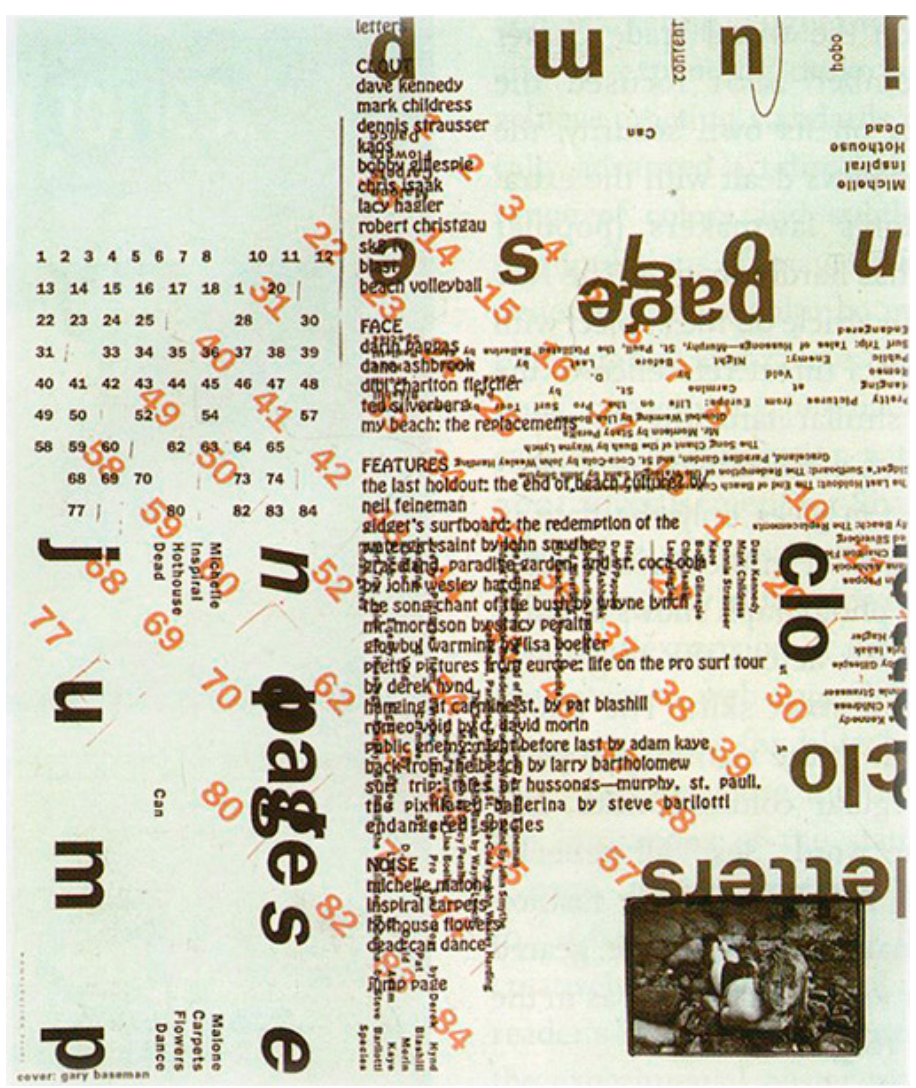

Figura 11 - Sumário da Revista Beach Culture.

(http://www.studyblue.com/notes/note/n/test-4/deck/6185782)

Outra figura do design gráfico que se destacou nos movimentos de contracultura dos anos 80, foi Neville Brody, diretor de arte da revista "The Face". Esta publicação possuía estética gráfica radical, fazendo referência clara aos movimentos construtivista, dadaísta e expressionista, ao mesmo tempo em que espelhava a imagem e atmosfera do punk rock. "Era uma união de cultura visual e rebelião política" (ZAPPATERRA, 2008, p:166). Nas páginas desta revista, Brody rompeu com os métodos tradicionais de construção dos caracteres tipográficos, transformando-os em elementos gráficos versáteis, maleáveis, compostos juntamente com as imagens e criando significado próprio, como exemplificado na figura 12.

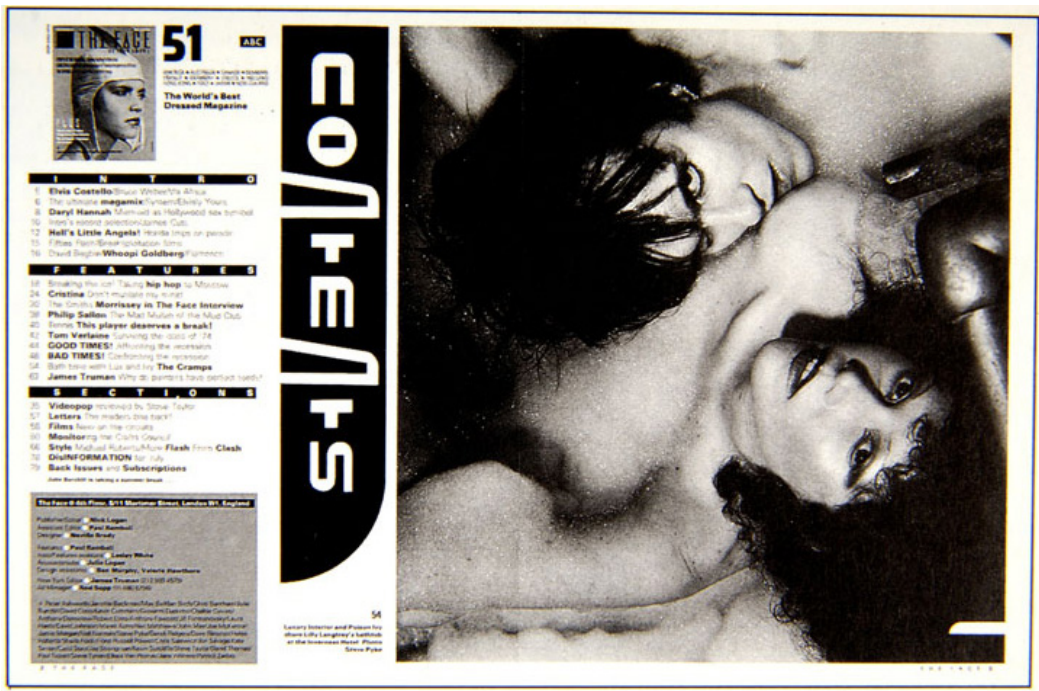

Figura 12 - Revista da The Face (fonte: HOLLIS, 2000, p. 207) 
"SoDA" é uma revista suíça, lançada em 1997, que se posicionava como "uma revista para um estilo de vida mental". Seu nome vem de uma expressão alemã similar à francesa "voilá", ou ainda "Ecco!", fazendo também uma importante referência ao dadaísmo e a seu modo de ver as coisas. A relação com o ilógico e o acaso começa com o fato da revista não possuir um projeto gráfico estabelecido e cada número ter marca, capa e formatos diferentes. A proposta era que cada número lançado afrontasse o número precedente (ZAPPATERRA, 2008, p:110). Na figura 13 são apresentadas dois exemplos de capa.

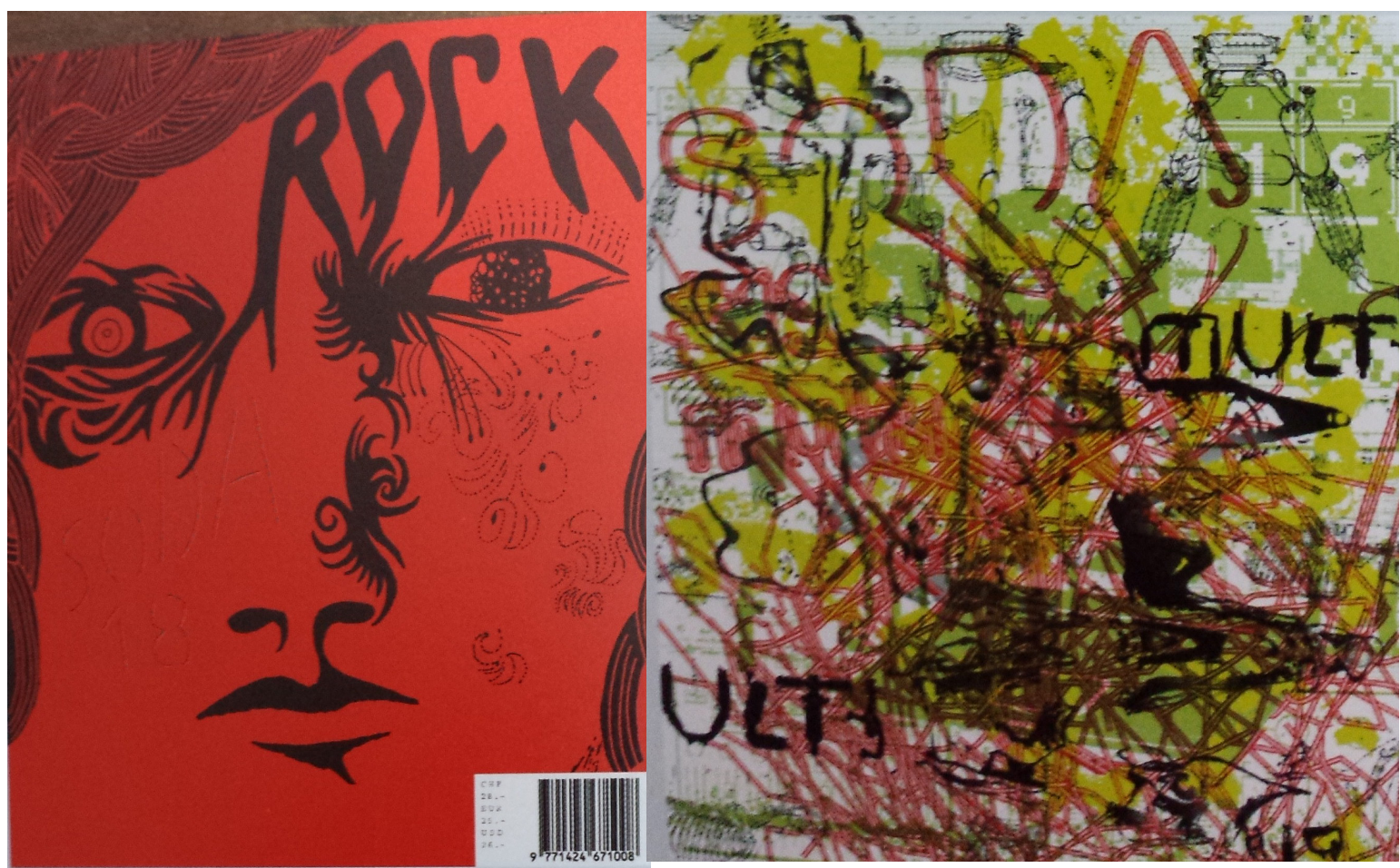

Figura 13: Capas da revista SoDA. (ZAPPATERRA, 2008, p:110)

Por fim, uma outra publicação que também encarna a ideia da palavra imagem é a "Zembla". Lançada em 2004 e projetada por Vince Frost (da EmeryFrost, em Melbourne) e Matt Willey (da Frostdesign, em Londres) tinha como lema "divertir-se com as palavras". Sua abordagem frenética e irreverente da tipografia, combinada a uma estrutura gráfica audaciosa, resultava muitas vezes em um texto ilegível, conforme mostrado na figura 14. Sua proposta extrema, baseada no desejo de provar coisas diferentes, buscava, segundo Frost, não aborrecer o leitor e o escritor, evitando fazer sempre a mesma coisa (ZAPPATERRA, 2008, p:139). 


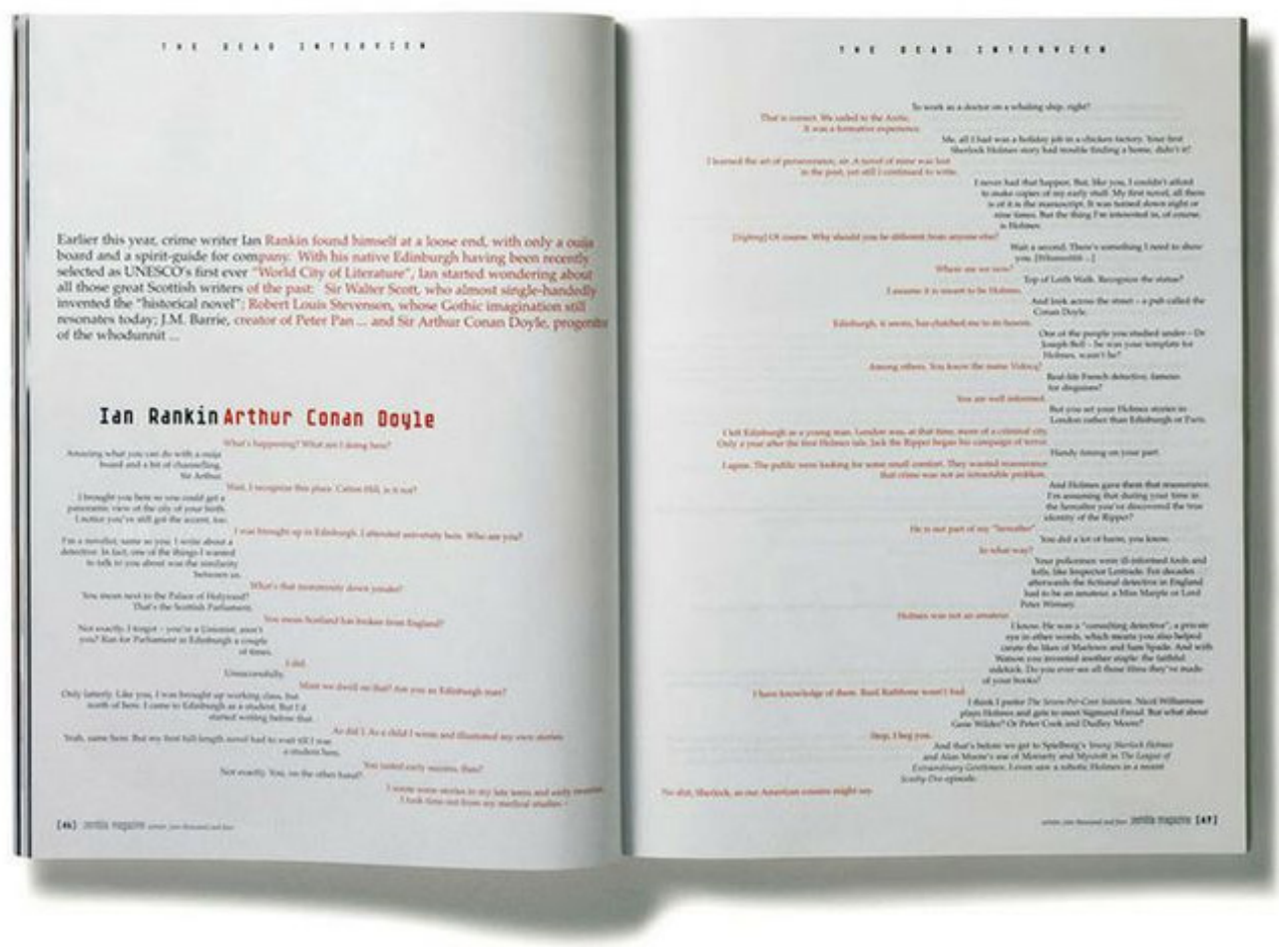

Figura 14: Exemplo páginas internas da Revistas Zembla.

(http://media-cache-ec0.pinimg.com/736x/42/6e/1d/426e1d6550fe3a89a1fb9e71aec1bc8b.jpg)

\section{Considerações Finais}

Os movimentos artístico-culturais do século XX, englobando tanto os do início, como o Futurismo, quanto os do final, ligados à contracultura, espelhavam em suas obras o contexto social vivido, questionando, em ambos os períodos, tradições e dogmas da sociedade. Nestes movimentos, tipógrafos, artistas gráficos e designers buscavam abandonar um fazer tipográfico voltado para a leitura contínua, baseada em padrões mais rígidos e lineares de ordem, de hierarquia e de harmonia visual e que, em suas concepções, estavam ligados aos valores que queriam rechaçar.

Fazendo um paralelo, na lógica da composição clássica, a tipografia deveria ser fundamentalmente trabalhada como uma interface para garantir harmonia e conforto no fluxo da leitura. Já nos movimentos de contracultura, a tipografia passa a ser considerada como o item de destaque que objetiva atrair o olhar e prender a atenção do leitor. Buscava explorar a liberdade, a flexibilidade e a criatividade. Como resultado, a desconstrução e o uso da palavra como imagem foram transformados em elementos fundamentais para a criação de novos significados na página e, consequentemente, usados para transmitir uma outra visão da sociedade e do mundo.

Exercendo seu papel enquanto vanguarda, os novos valores que emergiam do questionamento das regras estabelecidas na sociedade eram convertidos em diretrizes inovadoras para a construção de páginas tipográficas semanticamente mais ricas, que ao ganharem as ruas, disseminavam seus conteúdos mais fortemente. Desta forma, propuseram não somente novas ideias sociais, mas também novas formas de jogar com a mancha gráfica, usando os caracteres e as palavras como elementos de ilustração da página, libertando a tipografia da restrita tarefa de apresentar o conteúdo verbal que lhe é inerente. Foram além e permitiram que as letras fossem en- 
caradas tanto como elementos formadores da imagem quanto como imagens em si mesmas, abrindo espaço para uma nova visão da tipografia. 


\section{Referências Bibliográficas}

BARTRAM, Alan. Futurist typography and the liberated text. $1^{\underline{a}}$ ed. New Haven: Yale University Press, 2004. 160p.

BRINGHURST, Robert. Elementos do estilo tipográfico. 1a ed. São Paulo: Cosac Naify, 2005. 428p.

GAUDÊNCIO, Norberto. A herança escultórica da tipografia. 1a ed. São Paulo: Edições Rosari, 2004. 127p.

HOLLIS, Richard. Design Gráfico - Uma história concisa. 1aㅡ ed. São Paulo: Martins Fontes, 2000. 248p.

HOUAISS. Dicionário da Língua Portuguesa. Disponível em: http://houaiss.uol. com.br/. Acessado em 20 de agosto de 2014.

MARCH, Fundación Juan. La vanguardia aplicada (1890-1950) [cat. expo., Fundación Juan March, Madrid]. Madrid: Fundación Juan March, 2012, 469p.

MEGGS, Philip B; PURVIS, Alston W. História do Design Gráfico. 1a ed. São Paulo: Cosac Naify, 2009. 720p.

SAMARA, Timothy. Typography Workbook: A Real-World Guide to Using Type in Graphic Design. 1a ed. Gloucester: Rockport Publishers, 2006. 240 p.

SPENCER, Herbert. Pioneros de la Tipografia Moderna. 1a ed. México: Ediciones Gustavo Gili, 1990, 160p.

ZAPPATERRA, Yolanda. Professione: gráfico editoriale. Modena: Logos, 2008, $208 p$. 